\title{
Level of Language Proficiency of Gulf College Students
}

\author{
Dr. LeovigildoLito D. Mallillin, Dr. Romeo C. Castillo \\ FFS,LecturerFaculty of Foundation StudiesGulf College, Sultanate of Oman
}

\begin{abstract}
This study aimed to examine the level of language proficiency of college students. This study used the descriptive correlation research since it describes the phenomena being studied.The researcher employed purposive sampling. Out of the twenty seven (27) batches enrolled in semester 1 and 2 eleven (11) batches were utilized as respondents which composed of three hundred forty nine (349) respondents.Result showed that identifying errors, writing, correct usage, reading and listening skills were significantly affected by the respondents' profile. However, speaking and vocabulary skills show that they are not significantly. The level of their language proficiency in terms of listening, reading and writing are above average while speaking, vocabulary, identifying of errors and correct usage are average. The relationship between the profile of the respondents and their level of proficiency showed that their listening, reading, writing, identifying of errors, and correct usage skills is highly significant while speaking and vocabulary skills is not significant.
\end{abstract}

Key words:Language Proficiency, listening skills, speaking skills, reading skills, writing skills, vocabulary skills, identifying of errors and correct usage.

\section{INTRODUCTION}

Nowadays schools are confronted with problems on low language performance of the students. Despite of the repeated learning given to students by their teachers particularly on the construction of grammars, spelling, writing techniques, readings and even their comprehension level is remarkable as based on the experiences of the researcher as an English language lecturer. As cited by (Doherty, \&Hilberg, 2007) found out that (a) teacher use of the standards for effective pedagogy reliably predicted performance on year-end standardized tests of comprehension, reading, spelling, and vocabulary and (b) achievement gains were greatest for students whose teachers made extensive use of the standards and organized their classrooms into multiple, simultaneous, diversified activity settings. Although low-English-proficient students benefited the most, the instructional model was also effective for English learners and English speakers. This proves that the result will be of great help to low learner students to improve with their English proficiency level.

The problem that can still be encountered by the students is their native tongue spoken in their homes and their peers. This influences them to poor performance in their English language and proficiency. Therefore, schools or colleges are under increasing pressure to reclassify their English learner (EL) students to "fluent English proficient" status as quickly as possible(Umansky, \& Reardon, 2014).

Indeed, that low language performance of students is affected by their own language and English for them is a foreign language not even their second language. This emphasizes that most students are facing some problems in learning English as a second or foreign language in non-English speaking country, because of this weaknesses towards English language learning, students explore their language proficiency to minimize their poor language proficiency. English students-teachers must responds to their needs to address their poor English language performance. English language is difficult to learn due to students are not well-motivated, encouraged and gained learning strategy. Students do not practice speaking English with English speakers and class environment is crowded and noisy that is not fulfilled with teaching pedagogy (Souriyavongsa, Rany, Abidin, \&Mei, 2013).

The globalisation of education has meant that English medium universities are enrolling unprecedented numbers of students for whom English is not a first language. This, in turn, has put increased pressure on institutions to ensure they have in place suitable measures for screening applicants in respect of their English language proficiency and providing suitable support post-entry for those students who succeed in meeting English language entry criteria but still struggle to meet the linguistic demands of their programs of study. An effort to improve these processes have recently been galvanized by the requirement regulatory requirements, one effect of which has been a significant increase in activity around the area of post-enrolment language assessment, with the purpose of identifying all students potentially at risk and ensuring, subsequently, that mechanisms are in place that promise to address their language needs effectively. This considers some of the issues around post-enrolment English language assessment, discusses possible permutations for its implementation, and argues that, in determining the focus of such assessment, it is helpful to deconstruct the 
generic term "proficiency".(Murray, 2010).Schools at present have programs to help improve the language proficiency of students in their language learning.

Therefore, low performance of students in their language proficiency can be addressed by the English teachers to encourage the students to talk in English only. This act makes themconfident. By taking extra care, the English teacher will impart the nuancesspoken aspects of a language once/twice in a week as a remedial measure. When such type of spoken English classes begins, student-friendly orlearner-centric environment will certainly prevail, as more and morestudents will participate in the session. Teachers should motivate studentsfor participative learning. This will solve all the stumbling blocks instudents. Teaching learning is not a one-way process. It is a multi-wayprocess. As soon as the teaching is over, students should raise their doubts,clarification, etc. By doing so, students' communication skills in Englishwill grow. To develop this, sufficient practice must be given to students' intheir preliminary stage. While maintaining classroom managementconcurrently learnerfriendly atmosphere should also prevail there. Thisensures students to learn more and participate more. Above all, a teacher isnot only a teacher but also a friend, guide and a philosopher to students.He/she guides students not only to pass in the exam but also to facechallenges and take right decisions during the time of crisis in life. This is,of course, a real and tough task ahead of a good teacher (Kannan, 2009).

\section{STATEMENT OF THE PROBLEM}

1. What is the profile of the respondents in terms of

1.1 age,

1.2 years of studying English

1.3 exposure to English reading materials, and

1.4 exposure to English movies and television?

2. What is the level of language proficiency in terms of

2.1 listening skills,

2.2 speaking skills,

2.3 reading skills,

2.4 writing skills,

2.5 vocabulary skills,

2.6 identifying errors skills and

2.7 correct usage skills?

3. Is there a significant relationship between the profile of the respondents and the level of language proficiency among them?

\section{Research Design}

\section{METHOD}

This study used the descriptive correlation research since it describes the phenomena being studied. The purpose of this descriptive correlational research is to determine the relations among two or more variables (Lomax \& $\mathrm{Li}, 2013$ ). Data are gathered from the profile of the respondent as to age, number of years in studying English, exposure to English reading materials and exposure to English media. Other variables are the level of proficiency of the respondents in terms of listening, speaking, reading, writing, vocabulary, identifying of errors and correct usage of skills. After the important variables have been identified, the relations, levels, degrees and influence among those variables are investigated (Lomax \& Li, 2013).

\section{Research Subject}

The subjects of the study are the college students of Gulf College who have enrolled in semesters 1 and 2 who have subjects in listening, speaking, writing, reading and communication skills.

\section{Research Locale}

This study is conducted at Gulf College which is located at Maabella, Sultanate of Oman. It is a private school that caters the needs of the students in their place. They have programs to enhance students in their language proficiency, thus preparing them for their future. One of the programs offered is the Faculty of Foundation Studies (FFS) which programs deal on the basic foundation of learning among the students particularly on their English proficiency. This is also in preparation for promoting to their next level of their studies. 


\section{SAMPLING TECHNIQUE}

The researchers employed purposive sampling. Purposive sampling is intentional selection of informants based on their ability to elucidate a specific theme, concept, or phenomenon (Robinson, 2014). A deliberate selection of individuals made by the researcher based on the predefined criteria. Out of the twenty seven (27) batches enrolled in semesters 1 and 2 eleven (11) batches were utilized as respondents which composed of three hundred forty nine (349) only.

\section{RESEARCH INSTRUMENT}

The researchers used a set of questionnaire that elicited the needed data and information on matters that pertained to the topic under study. This consisted of different parts and each for specific purpose. Part 1 collected data and information on the profile of the respondentsand Part 11 collected data and information on listening, speaking, reading, writing, vocabulary, identifying errors and correct usage. Each examination parts were composed of 1 to 10 items only. The respondents were given enough time to go over the questionnaire and answered the test based on their analysis, comprehension and understanding. In every examination part directions were given for the respondents to follow. The questionnaire used was a standardized questionnaire to determine the English proficiency of the students.

The following respective scales are follows in terms of measuring their level of proficiency in their English.

1. Profile of the Respondents

Percentage was used to find the ratio of frequency of response to the total number of respondents by applying this formula:

$$
P=\frac{f}{N} \times 100
$$

Where:

$$
\begin{array}{ll}
\mathrm{P} & =\text { percentage } \\
\mathrm{f} & =\text { frequency } \\
\mathrm{N} & =\text { no. of respondents }
\end{array}
$$

\section{Level of English Proficiency}

The weighted mean was used to measure the wholistic view of the respondents' responses. The formula is:

$$
\text { Where: } \begin{aligned}
\text { WM }= & \frac{\sum \mathrm{fw}}{\mathrm{N}} \\
\mathrm{WM} & =\text { weighted mean } \\
\sum \mathrm{fw} & =\text { sum of the product of the frequency } \\
\mathrm{N} & =\text { no. of respondents }
\end{aligned}
$$

3. The standard deviation was used to show the heterogeneity or the homogeneity of the respondents.

The formula is:

$$
\mathrm{S}=\sqrt{ } \mathrm{N} \sum \mathrm{x}^{2}-\left(\sum \mathrm{x}\right)^{2}
$$

$$
\mathrm{N}(\mathrm{N}-1)
$$

Where:

$$
\begin{array}{ll}
\mathrm{SD} & =\text { standard deviation } \\
\mathrm{N} & =\text { no. of scores } \\
\sum \mathrm{x} & =\text { summation of scores }
\end{array}
$$

4. Significant relationship between the profile and the level proficiency

Multiple regression was used to predict the dependent variables y given to the independent variables $\mathrm{X}_{\mathrm{s}}$ among the respondents using the following formula:

Where:

$$
Y=b_{o}+b_{1} X_{1}+b_{2} X_{2}+\ldots+b_{n} X_{n}
$$

$$
\begin{array}{ll}
\mathrm{Y} & =\text { the dependent variable to be predicted } \\
\mathrm{X}_{1} \mathrm{X}_{2} \ldots \mathrm{X}_{\mathrm{n}} & =\text { the known independent variables that may influence } \mathrm{y}
\end{array}
$$




$$
\mathrm{b}_{\mathrm{o}}, \mathrm{b}_{1} \mathrm{~b}_{2} \ldots \mathrm{b}_{\mathrm{n}} \quad=\text { numerical constants which must be determined from }
$$
observed data

5. Scale Description

Scale

2.10-3.00

$1.10-2.00$

$0.00-1.00$
Description

Above Average

Average

Below Average
Description Interpretation

The students have better language proficiency

The students have a good language proficiency

The students have low language proficiency

\section{THEORETICAL FRAMEWORK}

This study is anchored on the Communicative Language Teaching: Linguistic Theory and Classroom Practice, as cited by (Savignon,2002)as this theory deals on Communicative Language Teaching (CLT) which refers to both processes and goals in classroom learning. The central theoretical concept in communicative language teaching is communicative competence, a term introduced into discussions of language use and second or foreign language learning. Competence is defined in terms of the expression, interpretation, and negotiation of meaning and looks to both psycholinguistic and socio-cultural perspectives in second language acquisition (SLA) research to account for its development.

\section{CONCEPTUAL FRAMEWORK}
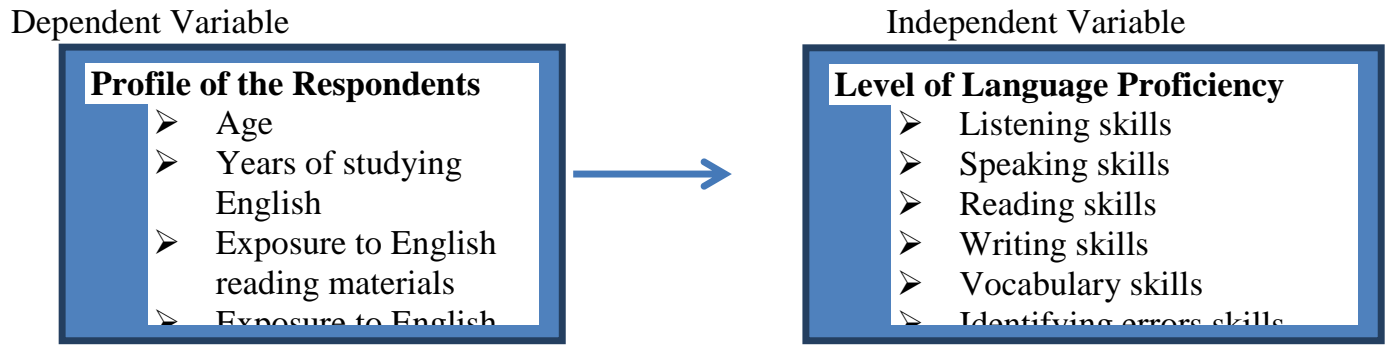

Figure 1.0

RESULTS

Table 1.1 Profile of the Respondents

\begin{tabular}{|l|c|c|c|}
\hline & Frequency & Percentage & Ranking \\
\hline Age: & & & \\
& 145 & 41.5 & 1 \\
19 years and below & 135 & 38.7 & 2 \\
20-21 years & 69 & 19.8 & 3 \\
\hline 22 years and above & & & \\
\hline Years of studying English: & 30 & 8.6 & 3 \\
5 years and below & 67 & 19.2 & 2 \\
6-10 years & 252 & 72.2 & 1 \\
11 years and above & & & \\
Never at all & 14 & 4.0 & 4 \\
Once a day & 221 & 63.3 & 1 \\
Once a week & 99 & 28.4 & 2 \\
Once a month & 15 & 4.3 & 3 \\
\hline Never at all & & & \\
Once a day & 19 & 5.4 & 3 \\
Once a week & 224 & 64.2 & 1 \\
Once a month & 89 & 25.5 & 2 \\
\hline
\end{tabular}

Table 1.1 presents the frequency and percentage distribution of the profile of the respondents. It shows that most of the respondents' age belongs to 19 years and below with a frequency of 145 or $41.5 \%$ out of 349 respondents. Hence, Years of studying English shows that 252 or $72.2 \%$ out of 349 respondents. However, exposure to English reading materials indicates a frequency of 221 or $63.3 \%$ among the respondents. This 
indicates that language learning for them is important. Moreover, exposure to English media shows that 224 or $64.2 \%$ among them which is needed in their communication skills.

Table 1.2. Level of Language Proficiency

\begin{tabular}{|c|c|c|c|}
\hline $\begin{array}{l}\text { Language } \\
\text { Proficiency }\end{array}$ & $\begin{array}{l}\text { Standard } \\
\text { Deviation }\end{array}$ & $\begin{array}{c}\text { Average } \\
\text { Weighted } \\
\text { Mean }\end{array}$ & Description \\
\hline Listening Skills & 0.054 & 2.40 & Above Average \\
\hline Speaking Skills & 0.048 & 1.44 & Average \\
\hline Reading Skills & 0.034 & 2.18 & Above Average \\
\hline Writing Skills & 0.020 & 2.07 & Above Average \\
\hline Vocabulary Skills & 0.046 & 1.50 & Average \\
\hline Identifying Errors Skills & 0.029 & 1.85 & Average \\
\hline Correct Usage Skills & 0.100 & 1.93 & Average \\
\hline
\end{tabular}

Table 1.2 shows the level of language proficiency of the respondents. Listening skills (AWM=2.40), reading skills $(\mathrm{AWM}=2.18)$ and writing skills $(\mathrm{AWM}=2.07)$ which are above average and shows that students have better language proficiency. On the other hand, speaking skills (AWM=1.44), vocabulary skills $(\mathrm{AWM}=1.50)$, identifying errors skills $(\mathrm{AWM}=1.85)$ and correct usage skills $(\mathrm{AWM}=1.93)$ which are average and shows that students have a good language proficiency

Table 1.3 Significant Relationship between the Profile and Language Proficiency

\begin{tabular}{|ll|c|c|c|c|c|}
\hline Dependent Variable & $\begin{array}{c}\text { Multiple } \\
\mathrm{R}\end{array}$ & F-Value & $\begin{array}{c}\text { Significant } \\
\text { Value }\end{array}$ & $\begin{array}{c}\text { Interpretatio } \\
\mathrm{n}\end{array}$ & $\begin{array}{c}\text { Ran } \\
\mathrm{k}\end{array}$ \\
\hline 1. & Listening Skills & 0.225 & 3.646 & 0.003 & Significant & 5 \\
2. & Speaking Skills & 0.163 & 1.881 & 0.097 & Not & 6 \\
3. & Reading Skills & 0.232 & 3.910 & 0.002 & Significant & 4 \\
4. & Writing Skills & 0.244 & 4.348 & 0.001 & Significant & 2.5 \\
5. Vocabulary Skills & 0.140 & 1.374 & 0.233 & Significant & 7 \\
6. & Identifying Errors & 0.318 & 7.379 & 0.000 & Not & 1 \\
& Skills & 0.244 & 4.358 & 0.001 & Significant & 2.5 \\
7. & Correct Usage Skills & & & & Significant & \\
& & & & & Significant & \\
\hline
\end{tabular}

Source: Multiple Regression Results

Level of Significance: 0.05

As observed from the summary table of multiple regression and correlation analysis between the profile of the respondents and their language proficiency, it shows that identifying errors skills, writing skills, correct usage skills, reading skills and listening skills were significantly affected by the respondents' profile name: age, number of years studying English, exposure to English reading materials and exposure to English movies and televisions. This is evidenced by their corresponding P-Values of 0.000, 0.001, 0.002 and 0.003 respectively in which the results are greater than the significance level of 0.05 .

However, speaking skills and vocabulary skills show that they are not significantly related to the respondents' profile which resulted to their corresponding P-Value of 0.097 and 0.233 . The results are lesser than the level of significance of 0.05 .

\section{DISCUSSION}

The level of proficiency of students nowadays really alarming though the result of the study indicates that most of the young respondents are exposed to English level of learning since English is a part of their curriculum. It is not still enough for their learning process since English for them is a vehicle for their learning. Hence, a positive view of the experience of learning English was the strongest predictor of both motivated learning behavior and L2 proficiency, whereas the Ideal L2 self was only a significant factor among them (Lamb 2012).Significantly, the years of studying English play an important role among the respondents. It shows that most of them are studying English the moment they entered their beginner level of learning. English for them is their second language and there is a need for them to learn English because it is an international language among them. This is very important for them in their communication process and useful after finishing their degree. Because of their future, they are motivated to study English. English learning were used as a measure of English language achievement for them because students took English courses for both integrative 
and instrumental reasons as well as to fulfill the university English language requirement, the majority of students reported that instrumental reasons for studying English were more important than integrative reasons; that is to say, there was a significant difference between integrative motivation and instrumental motivation, integrative motivation significantly contributed to the students' strength of motivation, students' reasons of taking English to fulfill the university foreign language requirement was the significant predictor of their English course grades, and integrative motivation and instrumental motivation were the significant predictors of the students' desires to continue studying English beyond their fulfillment of the university English language requirement (Oranpattanachai, 2013).

Hence, exposure to reading materials has a great impact on the learning process of the respondents. It is evidently shows here that most of the respondents are willing to read English materials as a part of their learning process in the enhancement of their language proficiency. This study strongly suggests that adult learners can benefit from extensive and pleasure reading and that a well-equipped library, easy access to books, and encouragement and time to read are all key factors in the development of reading habits (Rodrigo, Greenberg, \& Segal, 2014).

Moreover, exposure to English media is one way of increasing their level of proficiency since most of the respondents are fund of exposing themselves in English media and in English television for them to enhance more in their English learning and proficiency. The influence of starting age and input on foreign language learning in relation to starting age influences early starters in instructional settings achieve the same kind of long-term advantage as learners in naturalistic settings and it complements by oral performance, the relative impact on learners' oral performance of different input measures: number of years of instruction, number of hours of curricular and extracurricular lessons, number of hours spent abroad in an English-speaking setting, and current contact with the target language. Film-retelling oral narratives from 160 learners of English are analysed in terms of fluency, lexical diversity, and syntactic complexity. Correlational and regression analyses show that input has a stronger association with measures of oral performance than starting age, and that cumulative exposure and, above all, contact with high-quality input are good predictors of learners' oral performance in the foreign language (Muñoz, 2014).

On the other hand, listening skills among the respondents' shows that it is significant among the respondents wherein listening skills must be more practiced for them to improve their language proficiency. They should explore more in listening like watching English movies and television. This could help them adapt their language proficiency. Oral language, indexed by vocabulary and morphosyntactic skills, emerged as the most powerful unique predictor of both reading and listening comprehension levels. Although there was a tendency of oral language to be more strongly related to L2 reading comprehension, its relationship with listening comprehension was comparable across the two language groups. Finally, individual differences in oral language skills emerged as the primary factor that explained the language group differences in text comprehension levels (Babayiğit, 2014).

Speaking skills shows not significant among the language proficiency of the respondents since English for them is not their native language. It is their second or foreign language. Others can speak because of the influence they have in their environment like family, friends and peers. The different circumstances under which infant and adult learners develop speaking skills, facilities or difficulties in both cases in order to focus on the real possibilities of adults to develop a high level ofspeaking proficiency.Therefore, the role of the teacher is important in order to improve the learners' skills, the features oforal communication that need to be improved and which strategies can be used to overcome the difficulties (Romero, 2014).

Reading skills is highly significant in the contribution of the level proficiency of the students as evidently shown in the result of the study. Respondents are exposed to English reading materials wherein it improves their language proficiency. Orthographic mapping (OM) involves the formation of letter-sound connections to bond the spellings, pronunciations, and meanings of specific words in memory. It explains how children learn to read words by sight, to spell words from memory, and to acquire vocabulary words from print as a sequence of overlapping phases, each characterized by the predominant type of connection linking spellings of words to their pronunciations in memory. During development, the connections improve in quality and wordlearning value, from visual non-alphabetic, to partial alphabetic, to full grapho-phonemic, to consolidated grapho-syllabic and grapho-morphemic. OM is enabled by phonemic awareness and grapheme-phoneme knowledge. OM to support sight word reading is facilitated when beginners are taught about articulatory features of phonemes and when grapheme-phoneme relations are taught with letter-embedded picture mnemonics (Ehri, 2014).

Writing skills also shows that it is highly significant as based on the result of the study because they are used to it, this enhances the respondents in their language proficiency. The respondents can write because it is being taught to them during their younger age upon entering their schooling for learning. They can write in their facebook account, messenger, tweeter and even blog. The effect of blogging and portfolio keeping on a group of pre-serviceteachers' writing skill in a compulsory writing course at a tertiary level English language teaching 
(ELT)program, specifically looked into to what extent receiving feedback from courseinstructor and peers created ownership in writing and also to what extent giving feedback to peers' writingthrough blogging and portfolios contributed to a group of prospective English language teachers' writing skill. As part of blogging and portfolio keeping feedback from course instructor and peers as well as providing feedback to other peers'writing, blogs and portfolios emerge as effective tools to integratefeedback practice into writing process, offering course instructors and students' ample time and practice outsideordinary English classes as a foreign language (EFL). The practice of blogging andportfolio keeping and specifically receiving and giving feedback both on paper and online contributes to studentteachers' writing skills significantly on basic elements of writing skills such as process, organization, content,language use, vocabulary, mechanics, and accuracy (Arslan, 2014).

Vocabulary skills of students are not significant in their level of proficiency because they are used to context analysis in their studies and as such this improves their skills in their language. Vocabulary learning is facilitated when spellings accompany pronunciations and meanings of new words to activate Orthographic mapping (OM). Teaching students the strategy of pronouncing novel words aloud as they read text silently activates $\mathrm{OM}$ and helps them build their vocabularies. Because spelling-sound connections are retained in memory, they impact the processing of phonological constituents and phonological memory for words (Ehri,2014). However, the English receptive and expressive vocabulary skills as combined contributions of home, teacher, and peer English exposure levels of their language proficiency. English exposure levels at home were uniquely and positively associated with children's English receptive and expressive vocabularies, whereas peer English exposure levels were uniquely and positively associated with children's English expressive vocabulary. Teachers' English exposure levels were not uniquely associated with children's English vocabulary. The importance of the home environment and peer experiences in the classroom for maximizing children's early English vocabulary skills (Palermo, Mikulski, Fabes, Hanish,Martin, \&Stargel2014).

On the level proficiency of students in terms of identifying of errors skills and correct usage skills are highly significant because language learning for them is important and as such proper guidelines on English grammars are given emphasis among them. This is important among them in their language proficiency.English is conceptualized in the domain of testing, and particularly the tendency to identify the concepts of 'standard English' and 'native English' with 'the language itself'. The traditional view on both cognitive and social grounds, arguing that the English encountered and appropriated by non-native speakers will inevitably be qualitatively different from 'standard English' models, and that the effectiveness of the resources learners do develop should be assessed, where appropriate, independently of linguistic criteria(Hall, (2014).

Therefore, language proficiency level of the students in terms of listening, speaking, reading, writing, vocabulary, identifying of errors and correct usage vary depends on their motive in learning the English. This level of learning will contribute to their language proficiency.

\section{CONCLUSIONS}

Based on the findings, it is concluded:

1.Profile of the respondents at their young age is exposed to studying English to improve their language proficiency. They are exposed to reading of English materials and are exposed to English media as part of their learning process in the enhancement of their language proficiency.

2. The level of their language proficiency in terms of listening, reading and writing are above average in which they are exposed to English reading materials and exposed to English media so with their writing skills. Hence; speaking, vocabulary, identifying of errors and correct usage are average in which they need to explore more so that their level of proficiency in English will not be affected.

3. The relationship between the profile of the respondents and their level of proficiency shows that their listening skills, reading skills, writing skills, identifying of errors skills, and correct usage skills is highly significant while speaking skills and vocabulary skills is not significant.

\section{RECOMMENDATIONS}

Based on the conclusions, it is recommended:

1. Respondents need to explore more in the language proficiency though they have studied English at their young age, exposed to English reading materials and exposed to English media. They need to continue to enhance more their language proficiency to have a better mastery of their level proficiency.

2. Respondents should explore more on their level of language proficiency in terms of listening skills, reading skills and writing skills though the result is above average. Proper skills in listening, reading and writing must be given emphasis to include techniques in such skills. However; in speaking skills, vocabulary skills, identifying of errors skills and correct usage skills. This must be given in their learning process since this is important in their language proficiency. The proper guidelines and rules in the English structure is necessity for their improve language learning. 
3. There is a need to explore more on the speaking skills and vocabulary skills because it is not significant, to include techniques in speaking, skills and correct usage of vocabulary in speaking. However, listening skills, reading skills, writing skills, identifying of errors skills and correct usage of skills is significant wherein a thorough study must be conducted like improvement of English grammars, technical writing and correct vocabulary to use in writing etc.

\section{REFERENCES}

[1] Arslan, R. S. (2014). Integrating feedback into prospective English Language Teachers' writing process via blogs and portfolios.TOJET: The Turkish Online Journal of Educational Technology, 13(1).

[2] Babayiğit, S. (2014). The role of oral language skills in reading and listening comprehension of text: A comparison of monolingual (L1) and bilingual (L2) speakers of English language. Journal of Research in Reading, 37(S1), S22-S47.

[3] Doherty, R. W., \&Hilberg, R. S. (2007).Standards for effective pedagogy, classroom organization, English proficiency, and student achievement.The Journal of Educational Research, 101(1), 24-35.

[4] Ehri, L. C. (2014). Orthographic mapping in the acquisition of sight word reading, spelling memory, and vocabulary learning.Scientific Studies of Reading, 18(1), 5-21.

[5] Hall, C. J. (2014). Moving beyond accuracy: from tests of English to tests of 'Englishing'. Elt Journal, 68(4), 376-385.

[6] Kannan, R. (2009). Difficulties in learning English as a Second Language. ESP world, 8(5), 1-4.

[7] Lamb, M. (2012). A self system perspective on young adolescents' motivation to learn English in urban and rural settings.Language Learning, 62(4), 997-1023.

[8] Muñoz, C. (2014). Contrasting effects of starting age and input on the oral performance of foreign language learners.Applied Linguistics, amu024.

[9] Murray, N. (2010). Considerations in the post-enrolment assessment of English language proficiency: Reflections from the Australian context. Language Assessment Quarterly, 7(4), 343-358.

[10] Oranpattanachai, P. (2013). Motivation and English Language Achievement of Thai Undergraduate Students.LEARN Journal: Language Education and Acquisition Research Network, 6(1), $26-48$.

[11] Palermo, F., Mikulski, A. M., Fabes, R. A., Hanish, L. D., Martin, C. L., \&Stargel, L. E. (2014). English exposure in the home and classroom: Predictions to Spanish-speaking preschoolers' English vocabulary skills. Applied Psycholinguistics, 35(06), 1163-1187.

[12] Rebecca S. Robinson. (2014). Encyclopedia of quality of life and well-being research.pp 5243-5245. Retrieved from link.springer.com/10.1007/978-94-007-0753-5_2337

[13] Richard Lomax \&Jian Li. (2013).Correlational Research.www.education.com > School and Academics , Classroom Learning

[14] Rodrigo, V., Greenberg, D., \& Segal, D. (2014).Changes in reading habits by low literate adults through extensive reading.Reading in a Foreign Language, 26(1), 73.

[15] Romero, B. N. (2014). Improving speaking skills.

[16] Savignon, S. J. (2002). Communicative language teaching: Linguistic theory and classroom practice. Interpreting communicative language teaching: Contexts and concerns in teacher education, 1-27.

[17] Souriyavongsa, T., Rany, S., Abidin, M. J. Z., \& Mei, L. L. (2013). Factors causes students low English language learning: A case study in the National University of Laos. International Journal of English Language Education, 1(1), 179-192.

[18] Umansky, I. M., \& Reardon, S. F. (2014). Reclassification patterns among Latino English learner students in bilingual, dual immersion, and English immersion classrooms. American Educational Research Journal, 51(5), 879-912. 